\title{
Understanding and Preventing Placenta-Mediated Pregnancy Complications
}

\author{
Leslie Skeith ${ }^{1}$ Marc Blondon ${ }^{2}$ Fionnuala Ní Áinle ${ }^{3}$ \\ ${ }^{1}$ Division of Hematology and Hematological Malignancies, \\ Department of Medicine, University of Calgary, Calgary, Canada \\ 2 Division of Angiology and Hemostasis, Department of Specialties of \\ Medicine, Faculty of Medicine, Geneva University Hospitals, Geneva, \\ Switzerland \\ ${ }^{3}$ Department of Haematology, School of Medicine, University College \\ Dublin, Rotunda Hospital and Mater University Hospital, Irish \\ Network for VTE Research (INViTE), Dublin, Ireland
}

Hämostaseologie 2020;40:356-363.

\author{
Address for correspondence Leslie Skeith, Division of Hematology \\ and Hematological Malignancies, Department of Medicine, University \\ of Calgary, 1403-29th Street NW, Calgary, AB T2N 2T9, Canada \\ (e-mail: laskeith@ucalgary.ca).
}

\begin{abstract}
Keywords

- pregnancy

- placental complications

- low-molecular-weight heparin

Placenta-mediated pregnancy complications are clinically important conditions and include preeclampsia, placental abruption, intrauterine growth restriction, and late fetal loss. Pathophysiology is complex, and may be linked to prothrombotic disorders such as antiphospholipid syndrome, whose understanding is still evolving. In this narrative review, we will present the latest evidence to better understand hemostatic mechanisms of preeclampsia, as well as in women with placenta-mediated pregnancy complications and inherited thrombophilia or antiphospholipid antibodies. Using four clinical scenarios, the mixed results of preventive efforts through the use of antithrombotic drugs (aspirin, heparin) will be discussed. We will also review knowledge gaps and ongoing research.
\end{abstract}

\section{Introduction}

Placenta-mediated pregnancy complications are a related but heterogenous group of disorders that include preeclampsia, placental abruption, intrauterine fetal growth restriction (leading to birth of a small-for-gestational age [SGA] infant), and late fetal loss. ${ }^{1}$ Placenta-mediated pregnancy complications are associated with significant maternal morbidity and are an important cause of iatrogenic delivery and adverse pregnancy outcomes including fetal death. Beyond the more immediate pregnancy complications, preeclampsia is an important prognostic factor for the development of future cardiovascular disease. ${ }^{2,3}$

While we can identify the negative impact that placental complications have on pregnancy outcomes and women's cardiovascular health, the underlying pathophysiology is still being defined and management of these conditions can be controversial. We present the latest evidence to better understand and manage pregnant women at risk of placenta- mediated pregnancy complications. Using four clinical scenarios, our article will review recent advances in the pathophysiology of preeclampsia, its prevention, and the management of pregnant patients with prior placenta-mediated pregnancy complications who have inherited thrombophilias and antiphospholipid syndrome (APS).

\section{Preeclampsia}

Case 1. A 30-year-old woman is at 10 weeks of her first pregnancy and enquires about the prevention of preeclampsia, from which her sister had suffered in the past. She is obese and has well-controlled type 2 diabetes.

Preeclampsia is a serious complication of pregnancy with potentially life-threatening consequences for both mother and baby. It is diagnosed by new-onset hypertension with proteinuria (>0.3 g/24hours), organ dysfunction, and/or edema after 20 weeks of gestation and can affect up to 2 to $8 \%$ of all pregnancies. ${ }^{4}$ Worldwide, an estimated 50,000 (c) 2020 Georg Thieme Verlag KG
Stuttgart · New York
DOI https://doi.org/ 10.1055/a-1184-8388. ISSN 0720-9355. 
women die annually from preeclampsia and a third of babies are born prematurely. ${ }^{4} \mathrm{~A}$ diagnosis of preeclampsia often coincides with a diagnosis of fetal growth restriction and a resultant therapeutic preterm delivery is a common consequence as the only curative treatment is delivery of the placenta. Early-onset preeclampsia (EOP), defined as preeclampsia onset prior to 34 weeks of gestation, is a rare variant of the disease spectrum associated with a higher rate of maternal and fetal complications. ${ }^{5}$ Preeclampsia is recognized by the American Heart Association as a gender-specific independent riskfactor for the development of cardiovascular disease. ${ }^{2}$ Women who have experienced any form of preeclampsia are at increased risk of postnatal cardiovascular disease with a similar risk to smokers (two to four times higher risk of death from cardiovascular disease), while patients with severe preeclampsia have up to 9.5 fold higher risk of death from future cardiovascular disease. , $3,5^{3}$ Moreover, preeclampsia is associated with postpartum VTE and risk of VTE even several years after pregnancy.,

Preeclampsia is characterized by abnormal placental vascular development with impaired invasion of the uterine spiral arteries by trophoblasts, resulting in fetal complications and maternal endothelial dysfunction. ${ }^{8,9}$ While the precise pathogenesis of preeclampsia remains to be fully characterized, it is accepted that tissue hypoxia and oxidative stress result in an imbalance of anti- and proangiogenic pathways and a maternal proinflammatory state..$^{8-18}$

Of potential relevance to cardiovascular complications, preeclampsia is also characterized by abnormalities in proand anticoagulant, fibrinolytic pathways and changes in platelet function, morphology, and numbers. ${ }^{5}$ Predicting a woman's overall hemostatic balance and in particular whether her individual risk leans toward thrombosis or bleeding can be challenging. On the one hand, several studies have reported increased procoagulant mechanisms, particularly in late-onset preeclampsia. ${ }^{19}$ On the other hand, competing decreases in anticoagulant mechanisms have been reported, particularly in more severe forms of preeclampsia such as EOP; in a recent prospective study, increased tissue factor pathway inhibitor activity and increased activated protein C sensitivity were reported in women with EOP compared with healthy pregnant women. ${ }^{20}$ Altered markers of fibrinolytic activity in EOP have also been shown to correlate with other markers of severe disease, such as levels of the antiangiogenic factors SFLT- 1 and endoglin. ${ }^{21}$

As we will discuss next, aspirin has been shown to reduce the risk of preeclampsia in high-risk women. Platelets play a critical role not only in hemostasis and thrombosis, but they are now understood to have a much broader role in our health and in disease. Platelets are the "first responders" at sites of tissue injury and are implicated in inflammation, wound healing, and tissue regeneration. ${ }^{22}$ Platelets and bioactive substances released by platelets play a critical role in successful trophoblast invasion and development of fetomaternal circulation during normal pregnancy. ${ }^{23,24}$ Recurrent fetal loss and fetal growth restriction have been observed in pregnant women with essential thrombocythemia indicating the importance of platelets in early implantation. ${ }^{25,26}$ Moreover, in normal pregnancy, plate- lets undergo morphological changes and their activation is increased. ${ }^{5,27}$

Upon activation, platelets release a multitude of signaling factors collectively termed the platelet releasate (PR). ${ }^{28}$ Maternal PR enhances trophoblast invasion and drives placental bed angiogenesisas well as critical processes during normal placentation, and recently, PR contents have been shown to be altered in pregnant compared with nonpregnant women. ${ }^{23,29}$ The contents of the PR include extracellular vesicles (EVs): bioactive messengers containing miRNA and protein signals that regulate a diverse range of biologic and inflammatory pathologic processes. ${ }^{30} \mathrm{EVs}$ originate from platelets but also other cellular sources, including the placenta: syncytiotrophoblast-derived EVs, generated in response to placental hypoxia, have been postulated to play a role in mediating preeclampsia-induced maternal endothelial damage. ${ }^{31,32}$

In preeclampsia, EV, platelet, and coagulation changes are even more pronounced than in normal pregnancy and may contribute to disease pathophysiology. ${ }^{33}$ An exciting recent development was the uncovering of a potential mechanistic role for EVs in the pathogenesis of preeclampsia: injection of procoagulant EVs triggered the accumulation of activated platelets in the placenta, causing inflammasome activation within trophoblast cells, which resulted in a preeclampsialike phenotype in pregnant mice. ${ }^{34}$

\section{Preeclampsia Prevention}

Low-dose aspirin is recognized as an effective prevention of preeclampsia. A 2019 Cochrane meta-analysis of 77 trials (40,249 women), including individual patient data analysis for most large clinical trials, concluded that the risk of preeclampsia was $18 \%$ lower with low-dose aspirin (95\% CI, 12-23\%). ${ }^{35}$ The ASPRE trial, which tested aspirin $150 \mathrm{mg}$ daily in pregnant women at high-risk of preeclampsia by means of a somewhat complex screening algorithm (including clinical, vascular imaging, and blood markers), found a $62 \%$ reduction of the risk of preterm preeclampsia and a $28 \%$ of preterm and term preeclampsia. ${ }^{36}$ The absolute risk reductions were $2.7 \%$ (number needed to treat [NNT] of 37 ) and $3.1 \%$ (NNT of 32). In the recently published ASPIRIN RCT, low-dose aspirin commenced between 6 and $13+6$ weeks of pregnancy and continued until $36+7$ weeks significantly reduced the incidence of preterm birth before 37 weeks in nulliparous women (RR: $0.89,95 \% \mathrm{CI}$ : 0.81-0.98) but also perinatal mortality (RR 0.86 ), fetal loss (RR 0.86), early preterm delivery before 34 weeks (RR 0.75 ), and, of relevance to preeclampsia, delivery before 34 weeks with hypertensive disorders of pregnancy (RR: $0.38,95 \% \mathrm{CI}$ : $0.17-0.85){ }^{37}$

Important questions on aspirin dose, timing, and selection of women remain unanswered. Whether aspirin $\geq 100 \mathrm{mg}$ is more effective than $<100 \mathrm{mg}$ was suggested by a previous meta-analysis, if initiated early in pregnancy, ${ }^{38}$ and there may be some signal of greater risk reduction with aspirin $\geq 75 \mathrm{mg}$ than $<75 \mathrm{mg}$ for all timings of initiation. ${ }^{35}$ Alterations of aspirin pharmacokinetics or the increasing weights of 
pregnant women may support the hypothesis that greater doses of aspirin are needed, but no conclusions can be drawn at this time in the absence of head-to-head trials. ${ }^{39}$ Because the development of preeclampsia is thought to occur early in pregnancy, weeks prior to its clinical symptoms, an early initiation of low-dose aspirin ( $<16$ weeks) is logically preferred. However, there is no strong evidence of a difference between an early or late initiation when comparing different clinical trials.

The selection of women who benefit from aspirin is challenging, because of the difficulty in predicting preeclampsia, which remains uncommon $(<10 \%)$. The most predictive factor is a past history of the disease, and other strong clinical factors include chronic hypertension, multifetal gestation, pregestational diabetes, and renal or autoimmune disease. More precisely, the risk of preeclampsia can be estimated by a risk assessment model (Fetal Medicine Foundation), which was used in the ASPRE study, and includes three clinical factors-uterine artery velocimetric markers, measurements of pregnancy-associated plasma protein-A, and placental growth factor. ${ }^{40}$

Current guidelines do not suggest the use of this complex algorithm. The United States Preventive Services Task Force (USPSTF, 2014) recommends low-dose aspirin $(81 \mathrm{mg} / \mathrm{d})$ to women with $\geq 1$ high-risk factor (previous preeclampsia, multifetal gestation, chronic hypertension, pre-pregnancy diabetes, renal disease, and/or autoimmune disease) and suggests low-dose aspirin in the presence of multiple moderate risk factors, such as obesity, nulliparity of a family history of preeclampsia. ${ }^{41}$ The UK National Institute of Health and Care Excellence (NICE, 2019) advises to use low-dose aspirin (75-$150 \mathrm{mg} / \mathrm{d}$ ) from 12 weeks of gestation, with a similar (but not identical) approach of clinical risk factors. ${ }^{42}$ The need for improved simple risk prediction tools has been advocated for, because the USPSTF and NICE approaches have low sensitivities, particularly among nulliparous women (8-10\%) and low positive predictive values (13-15\%). ${ }^{43}$

Case 1. This patient has several moderate risk factors for preeclampsia (nulliparity, obesity, family history of preeclampsia) and a high-risk factor (diabetes). Low-dose aspirin should be offered and started around 12 weeks of gestation. A dose of $150 \mathrm{mg}$ per day could be considered, especially in case of an important weight change.

\section{Inherited Thrombophilia and Placenta- Mediated Pregnancy Complications}

Case 2. A 25-year-old generally healthy patient has suffered from two early pregnancy losses ( $<10$ weeks of gestation), with a normal gynecological workup. A full thrombophilia testing was normal except for the heterozygous presence of factor V Leiden (rs4524). Her gynecologist contacts you for advice on the use of antithrombotic treatments.

Inherited thrombophilias are genetic conditions that predispose an individual to venous thromboembolism (VTE) and include factor $\mathrm{V}$ Leiden, prothrombin gene mutation, protein $\mathrm{C}$ deficiency, protein $S$ deficiency, and antithrombin deficiency. It is mechanistically plausible that the hypercoagulability seen in patients with inherited thrombophilia could also interfere with placental function at the maternal-fetal interface, and theoretically lead to reduced vascular perfusion or ischemia from placental microthrombi. ${ }^{44}$ In earlier case-control studies, researchers identified a strong association between inherited thrombophilia and placental-mediated pregnancy complications; however, in more recent prospective cohort studies and meta-analyses, this association appears to be more modest and present with only some (sometimes severe) placenta-mediated pregnancy complications. ${ }^{45-47}$ In a meta-analysis of prospective cohort studies, there was a small increased risk of pregnancy loss among women with factor $\mathrm{V}$ Leiden mutation detected compared with no mutation (4.2 vs. $3.2 \%$, odds ratio [OR]: 1.52, 95\% confidence interval [CI]: 1.06-2.19), and no increased risk with other placenta-mediated pregnancy complications. ${ }^{46}$ Other meta-analyses that included case-control studies detected modest associations seen between factor $\mathrm{V}$ Leiden and prothrombin gene mutation and different placentamediated pregnancy complications. ${ }^{48-51}$ These data are supported by findings from a large Danish nested case-control study that found a weak association (OR: 1.4, 95\% CI: 1.1-1.8) between factor $\mathrm{V}$ Leiden and severe placenta-mediated pregnancy complications including severe preeclampsia, placental abruption, and SGA $<3$ rd percentile. ${ }^{52}$ Whether other inherited thrombophilia (protein C, S, antithrombin) cause pregnancyrelated complications is not well characterized, given their rarity. $^{49}$

\section{Management of Pregnant Patients with Inherited Thrombophiliaswith Prior Placenta-Mediated Pregnancy Complications or Recurrent Pregnancy Loss}

If we can identify an association between inherited thrombophilia and pregnancy complications, including pregnancy loss, should we then provide targeted treatment with anticoagulants during pregnancy to reduce placental hypercoagulability? While the use of low-molecular-weight heparin (LMWH) to prevent pregnancy complications has become widespread in clinical practice, we now have high-quality evidence to guide our practice. In an international open-label randomized controlled trial of 292 pregnant patients with inherited thrombophilia (85\% factor V Leiden or prothrombin gene mutation) and past placenta-mediated pregnancy complications (61\%) and/or who were at increased risk of VTE (44\%), there was no added benefit of LMWH prophylaxis for the primary composite outcome of placenta-mediated pregnancy complications (severe or EOP, SGA infant $<10$ th percentile, pregnancy loss, or VTE). ${ }^{53}$ The results of the TIPPS trial argue against use of LMWH prophylaxis to prevent future pregnancy complications in pregnant women with inherited thrombophilia.

When pooling the TIPPS study with seven previously published randomized trials comparing LMWH versus no LMWH to prevent prior late ( $\geq 10$ weeks' gestation) or recurrent early pregnancy loss, among the 483 patients with inherited thrombophilia, there was no significant difference in the live birth rates with the use of LMWH, compared with no 
LMWH use (relative risk: $0.81,95 \% \mathrm{CI}: 0.55-1.19) .{ }^{54}$ These findings are consistent with the results of AFFIRM, a metaanalysis of individual patient data from 963 eligible women from eight randomized trials of LMWH versus no LMWH to prevent recurrent placenta-mediated pregnancy complications, regardless of their thrombophilia status. ${ }^{1}$ In this metaanalysis, eligible women were included if they were pregnant at the time of the study with prior preeclampsia, placental abruption, birth of an SGA infant $<10$ th percentile, one pregnancy loss after 16 weeks' gestation, or two losses after 12 weeks' gestation. There was no additional benefit of LMWH use for the primary composite outcome of early-onset or severe preeclampsia, SGA infant $<5$ th percentile, late pregnancy loss $\geq 20$ weeks of gestation, or placental abruption leading to delivery, including in a subgroup of 403 participants who had an inherited thrombophilia. ${ }^{1}$

Based on the available data, guidelines recommend against screening patients for inherited thrombophilia in the setting of placenta-mediated pregnancy complications. ${ }^{55,56}$ There is an ongoing randomized trial called ALIFE2 (EudraCT ID: 2012001447-43), which evaluates LMWH versus no LMWH to improve live birth rates among pregnant patients with inherited thrombophilia and recurrent pregnancy loss. Any use of LMWH for this indication should be in a research setting like the ALIFE2 trial, which we hope will definitely answer this important question for patients and their physicians.

Case 2: The full thrombophilia testing was unnecessary in this patient. Nevertheless, she should be informed that the current (limited) evidence does not support the use of LMWH in this setting, and should be encouraged to enroll in the ALIFE2 trial if close to a participating center.

\section{Antiphospholipid Syndrome}

Case 3: A 35-year-old woman has suffered from a late fetal loss during her first pregnancy 1 year ago. While no gynecological or fetal cause was found, she has persistent triple positive results for antiphospholipid antibodies (APLAs). She has read that heparin may help reduce the risk of another pregnancy loss and asks for your advice.

Case 4: A 28-year-old woman had a first pregnancy complicated by a term preeclampsia with a delivery of a low birthweight newborn ( $<5$ th percentile). She underwent screening for APLAs, with isolated medium titers of anticardiolipin (aCL) antibodies. She is at 6 weeks of her second pregnancy, andhas already started low-dose aspirin. Her gynecologist is uncertain about the indication for heparin in addition to aspirin.

APS is a rare systemic autoimmune disorder that is characterized by persistently positive APLAs (aCLantibodies, anti- $\beta_{2}$ glycoprotein antibodies, or lupus anticoagulant [LAC]) and clinical manifestations of venous, arterial, or small vessel thrombosis or placenta-mediated pregnancy complications. APS may occur in the presence of autoimmune disorders such as systemic lupus erythematosus (SLE; APS) or in isolation (primary APS).The definition of placenta-mediated pregnancy complications from the revised Sapporo/Sydney criteria for APS is based on consensus developed for research purposes, and include at least one of three or more unexplained and consecutive early pregnancy losses $<10$ weeks' gestation, one or more late pregnancy loss $\geq 10$ weeks' gestation, or one or more preterm deliveries $<34$ weeks' gestation because of severe preeclampsia/eclampsia or recognized features of placental insufficiency. ${ }^{57}$ International efforts are currently underway to revise the definition of APS. ${ }^{58}$

There is a known strong association with LAC and aCLantibodies and late fetal loss. ${ }^{59}$ There is less information known about the risk of pregnancy loss in women who have $\beta_{2}$ glycoprotein antibody $\left(a \beta_{2} \mathrm{GP} 1\right)$ positivity, or the association with APLA and risk of recurrent early pregnancy loss. ${ }^{59}$ Somewhat surprisingly, the link between APLAs and other placenta-mediated pregnancy complications is less clear with mixed results from published studies. ${ }^{59,60}$ In two recent prospective cohort studies in pregnant patients with wellcharacterized APS, the risk of severe preeclampsia is approximately $10 \%{ }^{61,62}$ There is a higher risk of adverse pregnancy outcomes for those who have a positive LAC or are triple positive (positive LAC, aCL, and $a \beta_{2} \mathrm{GP} 1$ ). ${ }^{61,63}$ While we can identify a higher risk of late pregnancy loss and possible placenta-mediated pregnancy complications in pregnant women with APS, why these complications occur and how they are treated needs further exploration and study.

Antibodies directed against phospholipid-binding proteins, in particular to domain 1 of $\beta_{2} \mathrm{PGP} 1$, are thought to be pathogenic in APS. ${ }^{44,64}$ The a $\beta_{2}$ PG1 antibodies localize to the decidua and inhibit trophoblastic proliferation, syncytia formation, and the maternal decidual invasion required for successful placentation. ${ }^{65-67}$ Exactly how these antibodies lead to obstetrical complications, however, is poorly understood but is thought to via activation of inflammatory cascades. ${ }^{58,64}$

The complement system activation has emerged as a possible mechanism. ${ }^{68}$ The complement system is part of the innate immune system and is made up of the classical, lectin, and alternative pathways that consist of enzymes and regulatory proteins that converge at the level of $\mathrm{C} 3$, leading to the generation of the proinflammatory enzyme C5a and the membrane attack complex C5b-9. Abnormal complement activation is thought to initiate and amplify inflammation and neutrophil activation at the placenta, which may contribute to obstetrical complications including fetal loss. ${ }^{69-71}$ Recent evidence also suggests the role of complement dysregulation in the development of preeclampsia and fetal growth restriction through lectin pathway proteins. ${ }^{72}$ Evidence from mouse models and human studies supports the role of complement activation in the pathogenesis of obstetrical APS. Mice deficient in the complement components (factor C3, C4, C5, and factor B) and mice treated with inhibitors of complement activation (anti-C5 antibody, C5a receptor antagonist peptide, and antifactor $B$ antibody) are resistant to fetal loss induced by APLAs. ${ }^{70,71}$ In a prospective cohort of 487 pregnant patients with SLE and/or APLAs, circulating levels of complement activation byproducts $\mathrm{Bb}$ and sC5b-9 were higher as compared with healthy pregnant controls. ${ }^{69}$ Increased levels of $\mathrm{Bb}$ and $\mathrm{CCD} 5 \mathrm{~b}-9$ were associated with adverse obstetrical outcomes after controlling for 
confounding factors in the subgroup of APLA-positive patients. Chaturvedi and colleagues have recently discovered evidence of complement activation and germline mutations in patients with APS who develop catastrophic APS or thrombosis ${ }^{73}$; further research is still needed to clarify the role of complement in pregnant women with APS.

\section{Management of Pregnant Patients with Antiphospholipid Syndrome and Prior Placenta-Mediated Pregnancy Complications or Recurrent Early Pregnancy Loss}

The 2019 European League Against Rheumatism (EULAR) guidelines recommend LMWH/aspirin prophylaxis during pregnancy to prevent pregnancy loss for women with APS who have a history of three or more early ( $<10$ weeks' gestation) pregnancy losses or one or more late loss $(\geq 10$ weeks' gestation), and suggest use of either aspirin alone or LMWH/aspirin for women with two early losses or other placenta-mediated pregnancy complications. ${ }^{74}$ There is variation in other clinical practice guidelines, which suggest the use of LMWH/aspirin or aspirin alone for pregnant patients with APS and past pregnancy loss. ${ }^{55,56,75}$

The evidence to support the use of LMWH/aspirin prophylaxis in pregnancy to prevent recurrent pregnancy loss is mixed. The results of earlier randomized trials were positive and others showed no additional benefit to LMWH/aspirin use, compared with aspirin alone. ${ }^{49,76-80}$ Limitations to these trials included different definitions of pregnancy loss, varying antibody types and positivity (including lowtiter antibody positivity or lack of confirmatory testing), and high crossover rates. Other trials evaluating non-LMWH therapies have reported similar outcomes $(\sim 70 \%)$ in live birth rates with aspirin alone. ${ }^{58}$ There is even less evidence to support the use of LMWH/aspirin to prevent other placenta-mediated pregnancy complications, with only one small randomized trial that showed no added benefit to LMWH/aspirin versus aspirin alone. ${ }^{81}$

In an open-label randomized controlled trial of pregnant women who developed fetal growth restriction before 32 weeks' gestation, there was no added benefit of tinzaparin 4,500 units subcutaneously daily for treatment to improve fetal growth rate or birth weight adjusted for gestational age, compared with no tinzaparin. ${ }^{82}$ While this was an unselected population who developed fetal growth restriction, women with an inherited thrombophilia (15\%) or positive APLAs on at least one occasion (LAC: 26\%; aß2PG1: $4 \%$ ) were included. ${ }^{82}$

Despite the use of LMWH/aspirin prophylaxis during pregnancy in women with APS, a high rate of pregnancy loss (20-30\%) and other placenta-mediated pregnancy complications remain. ${ }^{61-63,83}$ Unfortunately, given the rarity of APS and the already widespread use of LMWH/aspirin to improve live birth rates, completing future large trials to further assess the efficacy of LMWH may not be feasible. This highlights the importance of evaluating alternative non-anticoagulant options in a research setting before they become widespread practice. In a retrospective cohort of high-risk APS pregnant patients, the addition of hydroxychloroquine improved live birth rates. ${ }^{84}$ The HYPATIA randomized controlled trial is ongoing and evaluates hydroxychloroquine versus placebo, in addition to standard of care, in pregnant patients with APS or positive APLA (EudraCT ID: 2016-002256-25). ${ }^{85}$ With a focus on targeting the potential proinflammatory effects of complement activation, the IMPACT study is a prospective cohort study of tumor necrosis- $\alpha$ blockage with certolizumab during pregnancy in patients with a positive LAC (clinicaltrials.gov ID: NCT 0315208).

Better understanding the pathophysiology of APS is needed, including the role of complement activation; so, we can look beyond anticoagulant therapies to improve the live birth rates and other pregnancy outcomes. We support the ongoing international collaborative research efforts for these uncommon and often challenging clinical scenarios.

Case 3: This woman has persistent high-risk APLA profile and a diagnosis of obstetrical APS can be made. Following current recommendations, this patient should start lowdose aspirin prior to conception and start prophylactic LMWH as soon as her second pregnancy is confirmed.

Case 4: The criteria for obstetrical APS are not fulfilled in this case, with a low-risk antibody profile. Low-dose aspirin is indicated for the prevention of preeclampsia, but whether LMWH should be added to aspirin is uncertain. The woman is informed of the lack of knowledge and decides to take lowdose aspirin without LMWH.

\section{Time Capsule}

- Preeclampsia poses enormous challenges including the need to protect a mother's health and life while considering the risks of delivery baby early.

- Building upon recent breakthroughs, preeclampsia diagnosis, prediction, and prognosis will be accurate and personalized by 2050, harnessing the power of artificial intelligence technology.

- By 2050, our current comprehension of secondary hemostasis will have evolved into a complex global invivo system linking coagulation proteins with blood cells, endothelial cells, complement, and inflammatory proteins, thus changing our approach, prediction, and treatment potential for placenta-mediated pregnancy complications.

Authorship

All authors (L.S., M.B., F.N.A.) contributed to writing the first and subsequent drafts of the manuscript.

Conflicts of Interest

L.S.: Honoraria from Leo Pharma; research funding from CSL Behring. M.B: no conflicts of interest. F.N.A.: Research funding (paid via an IIS to the host university) from Bayer, Leo Pharma, and Actelion.

Acknowledgments

We would like to acknowledge our thrombosis networks for their general support, including INVENT, CanVECTOR, and INViTE. 


\section{Authors}

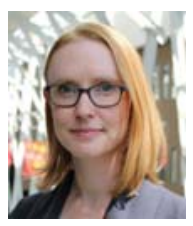

\section{Leslie Skeith}

Dr. Leslie Skeith is an early career researcher and an assistant professor in the Division of Hematology and Hematological Malignancies at the University of Calgary, Canada. Dr. Skeith completed a fellowship at the University of Ottawa in Thrombosis Medicine. Dr. Skeith's clinical and research interest is in the area of women's health and venous thromboembolism (VTE). Her research is in APS and placenta-mediated pregnancy complications, and preventing VTE in postpartum women with VTE risk factors.

Twitter: @leslieskeith

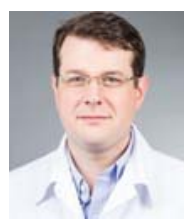

\section{Marc Blondon}

Dr. Marc Blondon is a hospital angiologist in the Division of Angiology and Hemostasis of the Geneva University Hospitals. After a clinical training in internal medicine, Dr. Blondon has completed a Master's Degree in Epidemiology at the University of Washington, Seattle, and clinical specialization in vascular medicine in Geneva. His research interest is focused on VTE, especially in the area of hormones, pregnancy, cost-effectiveness, and hospital thromboprophylaxis. He is actively involved in research studies with other European early career researchers and chairs the Early Career Committee of the International Society on Haemostasis and Thrombosis.

Twitter: @MarcBlondon

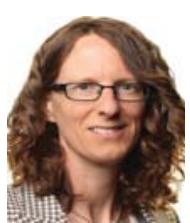

\section{FionnualaNíAinle}

Dr. FionnualaNíAinle is a hematologist at the Mater University Hospital and Rotunda Maternity Hospital, Dublin, and full clinical professor, School of Medicine, UCD. She is privileged to treat patients affected with thrombosis and has a strong interest in women's issues in thrombosis and hemostasis. She is a founder member of VTE Ireland, a National Clinical VTE Working Group, and is Director of the Irish network for VTE Research (www.INViTEresearch.org). Her research interests explore the role of blood coagulation and EVs in the etiology, management, and therapy of clinical disorders, particularly disorders of pregnancy. Along with Prof. Patricia Maguire, she codirects the UCD Conway Institute SPHERE Research Group (http://www. ucd.ie/conway/research/researchgroups/sphere/) and is actively involved in international clinical trials.

Twitter: @fniainle

\section{References}

1 Rodger MA, Gris JC, de Vries JIP, et al; Low-Molecular-Weight Heparin for Placenta-Mediated Pregnancy Complications Study Group. Low-molecular-weight heparin and recurrent placentamediated pregnancy complications: a meta-analysis of individual patient data from randomised controlled trials. Lancet 2016;388 (10060):2629-2641
2 Mosca L, Benjamin EJ, Berra K, et al; American Heart Association. Effectiveness-based guidelines for the prevention of cardiovascular disease in women-2011 update: a guideline from the American Heart Association. J Am Coll Cardiol 2011;57(12):1404-1423

3 Mongraw-Chaffin ML, Cirillo PM, Cohn BA. Preeclampsia and cardiovascular disease death: prospective evidence from the child health and development studies cohort. Hypertension 2010;56 (01):166-171

4 Saving Lives, Improving Mothers' Care: Lessons Learned to Inform Maternity Care from the UK and Ireland Confidential Enquiries into Maternal Deaths and Morbidity 2013-2015. 2017;1-104. https:// www.npeu.ox.ac.uk/downloads/files/mbrrace-uk/reports/ MBRRACE-UK\%20Maternal\%20Report\%202017\%20-\%20Web.pdf

5 Monteith C, Egan K, O'Connor H, et al. Early onset preeclampsia is associated with an elevated mean platelet volume (MPV) and a greater rise in MPV from time of booking compared with pregnant controls: results of the CAPE study. J Perinat Med 2018;46 (09):1010-1015

6 Jacobsen AF, Skjeldestad FE, Sandset PM. Ante- and postnatal risk factors of venous thrombosis: a hospital-based case-control study. J ThrombHaemost 2008;6(06):905-912

7 Scheres LJJ, Lijfering WM, Groenewegen NFM, et al. Hypertensive complications of pregnancy and risk of venous thromboembolism. Hypertension 2020;75(03):781-787

8 Fisher SJ. Why is placentation abnormal in preeclampsia? Am J ObstetGynecol 2015;213(4, Suppl):S115-S122

9 Rana S, Lemoine E, Granger JP, Karumanchi SA. Preeclampsia: pathophysiology, challenges, and perspectives. Circ Res 2019;124 (07):1094-1112

10 Redman CW, Sargent IL. Immunology of pre-eclampsia. Am J Reprod Immunol 2010;63(06):534-543

11 Huppertz B. Placental origins of preeclampsia: challenging the current hypothesis. Hypertension 2008;51(04):970-975

12 English FA, Kenny LC, McCarthy FP. Risk factors and effective management of preeclampsia. Integr Blood Press Control 2015; $8: 7-12$

13 Levine RJ, Lam C, Qian C, et al; CPEP Study Group. Soluble endoglin and other circulating antiangiogenic factors in preeclampsia. $\mathrm{N}$ Engl J Med 2006;355(10):992-1005

14 Venkatesha S, Toporsian M, Lam C, et al. Soluble endoglin contributes to the pathogenesis of preeclampsia. Nat Med 2006;12 (06):642-649

15 Schmella MJ, Roberts JM, Conley YP, et al. Endoglin pathway genetic variation in preeclampsia: a validation study in Norwegian and Latina cohorts. Pregnancy Hypertens 2018;12:144-149

16 Chau K, Hennessy A, Makris A. Placental growth factor and preeclampsia. J Hum Hypertens 2017;31(12):782-786

17 Pinheiro MB, Martins-Filho OA, Mota AP, et al. Severe preeclampsia goes along with a cytokine network disturbance towards a systemic inflammatory state. Cytokine 2013;62(01):165-173

18 Regal JF, Burwick RM, Fleming SD. The complement system and preeclampsia. Curr Hypertens Rep 2017;19(11):87

19 Macey MG, Bevan S, Alam S, et al. Platelet activation and endogenous thrombin potential in pre-eclampsia. Thromb Res 2010;125 (03):e76-e81

20 Egan K, O'Connor H, Kevane B, et al. Elevated plasma TFPI activity causes attenuated TF-dependent thrombin generation in early onset preeclampsia. ThrombHaemost 2017;117(08):1549-1557

21 Haire G, Egan K, Parmar K, et al. Alterations in fibrin formation and fibrinolysis in early onset-preeclampsia: association with disease severity. Eur J Obstet Gynecol Reprod Biol 2019;241:19-23

22 Parsons MEM, Szklanna PB, Guerrero JA, et al. Platelet releasate proteome profiling reveals a core set of proteins with low variance between healthy adults. Proteomics 2018;18(15):e1800219

23 Sato Y, Fujiwara H, Konishi I. Role of platelets in placentation. Med Mol Morphol 2010;43(03):129-133

24 Al Obaidly M, Regan C, Lwaleed BMN. A role for platelets in normal pregnancy. The non-thrombotic role of platelets in health and 
disease. InTech; 2015. https://www.intechopen.com/books/thenon-thrombotic-role-of-platelets-in-health-and-disease/a-rolefor-platelets-in-normal-pregnancy

25 Vantroyen B, Vanstraelen D. Management of essential thrombocythemia during pregnancy with aspirin, interferon alpha-2a and no treatment. A comparative analysis of the literature. Acta Haematol 2002;107(03):158-169

26 Falconer J, Pineo G, Blahey W, Bowen T, Docksteader B, Jadusingh I. Essential thrombocythemia associated with recurrent abortions and fetal growth retardation. Am J Hematol 1987;25(03):345-347

27 Morrison R, Crawford J, MacPherson M, Heptinstall S. Platelet behaviour in normal pregnancy, pregnancy complicated by essential hypertension and pregnancy-induced hypertension. ThrombHaemost 1985;54(03):607-611

28 Heijnen HF, Schiel AE, Fijnheer R, Geuze HJ, Sixma JJ. Activated platelets release two types of membrane vesicles: microvesicles by surface shedding and exosomes derived from exocytosis of multivesicular bodies and alpha-granules. Blood 1999;94(11):3791-3799

29 Szklanna PB, Parsons ME, Wynne K, et al. The platelet releasate is altered in human pregnancy. Proteomics Clin Appl 2019;13(03): e1800162

30 Szklanna PB, Parsons MEM, Wynne K, O’Connor H, Egan K, Ni Ainle FMP. The platelet releasate is a "barcode" for the health status of an individual. Res Pr ThrombHaemost 2017;1(Suppl 1):1-1451

31 Tannetta D, Masliukaite I, Vatish M, Redman C, Sargent I. Update of syncytiotrophoblast derived extracellular vesicles in normal pregnancy and preeclampsia. J Reprod Immunol 2017;119:98-106

32 Tannetta DS, Dragovic RA, Gardiner C, Redman CW, Sargent IL. Characterisation of syncytiotrophoblast vesicles in normal pregnancy and pre-eclampsia: expression of Flt-1 and endoglin. PLoS One 2013;8(02):e56754

33 Missfelder-Lobos H, Teran E, Lees C, Albaiges G, Nicolaides KH. Platelet changes and subsequent development of pre-eclampsia and fetal growth restriction in women with abnormal uterine artery Doppler screening. Ultrasound ObstetGynecol 2002;19 (05):443-448

34 Kohli S, Ranjan S, Hoffmann J, et al. Maternal extracellular vesicles and platelets promote preeclampsia through inflammasome activation in embryonic trophoblast. Blood 2016;128(17):2153-2164

35 Duley L, Meher S, Hunter KE, Seidler AL, Askie LM. Antiplatelet agents for preventing pre-eclampsia and its complications. (Review)Cochrane Database Syst Rev 2019;2019(10):1-281

36 Rolnik DL, Wright D, Poon LC, et al. Aspirin versus placebo in pregnancies at high risk for preterm preeclampsia. N Engl J Med 2017;377(07):613-622

37 Hoffman MK, Goudar SS, Kodkany BS, et al; ASPIRIN Study Group. Low-dose aspirin for the prevention of preterm delivery in nulliparous women with a singleton pregnancy (ASPIRIN): a randomised, double-blind, placebo-controlled trial. Lancet 2020;395(10220):285-293

38 Roberge S, Bujold E, Nicolaides KH. Meta-analysis on the effect of aspirin use for prevention of preeclampsia on placental abruption and antepartum hemorrhage. Am J ObstetGynecol 2018;218(05): 483-489

39 Rothwell PM, Cook NR, Gaziano JM, et al. Effects of aspirin on risks of vascular events and cancer according to bodyweight and dose: analysis of individual patient data from randomised trials. Lancet 2018;392(10145):387-399

40 Akolekar R, Syngelaki A, Poon L, Wright D, Nicolaides KH. Competing risks model in early screening for preeclampsia by biophysical and biochemical markers. Fetal Diagn Ther 2013;33(01): 8-15

41 LeFevre ML; U.S. Preventive Services Task Force. Low-dose aspirin use for the prevention of morbidity and mortality from preeclampsia: U.S. Preventive Services Task Force recommendation statement. Ann Intern Med 2014;161(11):819-826

42 Webster K, Fishburn S, Maresh M, Findlay SC, Chappell LC; Guideline Committee. Diagnosis and management of hyperten- sion in pregnancy: summary of updated NICE guidance. BMJ 2019;366:15119

43 Al-Rubaie ZT, Askie LM, Hudson HM, Ray JG, Jenkins G, Lord SJ. Assessment of NICE and USPSTF guidelines for identifying women at high risk of pre-eclampsia for tailoring aspirin prophylaxis in pregnancy: an individual participant data meta-analysis. Eur J Obstet Gynecol Reprod Biol 2018;229:159-166

44 Hossain N, Paidas MJ. Adverse pregnancy outcome, the uteroplacental interface, and preventive strategies. SeminPerinatol 2007; 31(04):208-212

45 Martinelli I, Taioli E, Cetin I, et al. Mutations in coagulation factors in women with unexplained late fetal loss. N Engl J Med 2000;343 (14):1015-1018

46 Rodger MA, Walker MC, Smith GN, et al. Is thrombophilia associated with placenta-mediated pregnancy complications? A prospective cohort study. J ThrombHaemost 2014;12(04):469-478

47 Rodger MA, Betancourt MT, Clark P, et al. The association of factor V Leiden and prothrombin gene mutation and placenta-mediated pregnancy complications: a systematic review and meta-analysis of prospective cohort studies. PLoS Med 2010;7(06):e1000292

48 Robertson L, Wu O, Langhorne P, et al; Thrombosis: Risk and Economic Assessment of Thrombophilia Screening (TREATS) Study. Thrombophilia in pregnancy: a systematic review. Br J Haematol 2006;132(02):171-196

49 Rey E, Kahn SR, David M, Shrier I. Thrombophilic disorders and fetal loss: a meta-analysis. Lancet 2003;361(9361):901-908

50 Lin J, August P. Genetic thrombophilias and preeclampsia: a metaanalysis. ObstetGynecol 2005;105(01):182-192

51 Howley HEA, Walker M, Rodger MA. A systematic review of the association between factor $\mathrm{V}$ Leiden or prothrombin gene variant and intrauterine growth restriction. Am J ObstetGynecol 2005; 192(03):694-708

52 Lykke JA, Bare LA, Olsen J, et al. Thrombophilias and adverse pregnancy outcomes: results from the Danish National Birth Cohort. J ThrombHaemost 2012;10(07):1320-1325

53 Rodger MA, Hague WM, Kingdom J, et al; TIPPS Investigators. Antepartum dalteparin versus no antepartum dalteparin for the prevention of pregnancy complications in pregnant women with thrombophilia (TIPPS): a multinational open-label randomised trial. Lancet 2014;384(9955):1673-1683

54 Skeith L, Carrier M, Kaaja R, et al. A meta-analysis of lowmolecular-weight heparin to prevent pregnancy loss in women with inherited thrombophilia. Blood 2016;127(13):1650-1655

55 Bates SM, Greer IA, Middeldorp S, Veenstra DL, Prabulos A-M, Vandvik PO. VTE, thrombophilia, antithrombotic therapy, and pregnancy: antithrombotic therapy and prevention of thrombosis, 9th ed: American College of Chest Physicians Evidence-Based Clinical Practice Guidelines. Chest 2012;141(2, Suppl):e691S-e736S

56 Chan WS, Rey E, Kent NE, et al; VTE in Pregnancy Guideline Working Group; Society of Obstetricians and Gynecologists of Canada. Venous thromboembolism and antithrombotic therapy in pregnancy. J Obstet Gynaecol Can 2014;36(06):527-553

57 Miyakis S, Lockshin MD, Atsumi T, et al. International consensus statement on preliminary classification criteria for definite antiphospholipid syndrome. J ThrombHaemost 2006;42:295-306

58 Branch DW. What's new in obstetric antiphospholipid syndrome. Hematology (Am Soc Hematol Educ Program) 2019;2019(01): 421-425

59 Abou-Nassar K, Carrier M, Ramsay T, Rodger MA. The association between antiphospholipid antibodies and placenta mediated complications: a systematic review and meta-analysis. Thromb Res 2011;128(01):77-85

60 Skeith L, Abou-Nassar KE, Walker M, et al. Are anti- $\beta 2$ glycoprotein 1 antibodies associated with placenta-mediated pregnancy complications? A nested case-control study. Am J Perinatol 2018; 35(11):1093-1099

61 Yelnik CM, Laskin CA, Porter TF, et al. Lupus anticoagulant is the main predictor of adverse pregnancy outcomes in aPL-positive 
patients: validation of PROMISSE study results. Lupus Sci Med 2016;3(01):e000131

62 Bouvier S, Cochery-Nouvellon E, Lavigne-Lissalde G, et al. Comparative incidence of pregnancy outcomes in treated obstetric antiphospholipid syndrome: the NOH-APS observational study. Blood 2014;123(03):404-413

63 Saccone G, Berghella V, Maruotti GM, et al; PREGNANTS (PREGNancy in women with ANTiphospholipid Syndrome) working group. Antiphospholipid antibody profile based obstetric outcomes of primary antiphospholipid syndrome: the PREGNANTS study. Am J ObstetGynecol 2017;216(05):525.e1-525.e12

64 Chaturvedi S, McCrae KR. Diagnosis and management of the antiphospholipid syndrome. Blood Rev 2017;31(06):406-417

65 Agostinis C, Biffi S, Garrovo C, et al. In vivo distribution of $\beta 2$ glycoprotein I under various pathophysiologic conditions. Blood 2011;118(15):4231-4238

66 Di Simone N, Raschi E, Testoni C, et al. Pathogenic role of anti- $\beta 2$ 2glycoprotein I antibodies in antiphospholipid associated fetal loss: characterisation of $\beta 2$-glycoprotein I binding to trophoblast cells and functional effects of anti- $\beta 2$-glycoprotein I antibodies in vitro. Ann Rheum Dis 2005;64(03):462-467

67 Di Simone N, Meroni PL, de Papa N, et al. Antiphospholipid antibodies affect trophoblast gonadotropin secretion and invasiveness by binding directly and through adhered beta2-glycoprotein I. Arthritis Rheum 2000;43(01):140-150

68 Chaturvedi S, Brodsky RA, McCrae KR. Complement in the pathophysiology of the antiphospholipid syndrome. Front Immunol 2019;10:449

69 Kim MY, Guerra MM, Kaplowitz E, et al. Complement activation predicts adverse pregnancy outcome in patients with systemic lupus erythematosus and/or antiphospholipid antibodies. Ann Rheum Dis 2018;77(04):549-555

70 Girardi G, Berman J, Redecha P, et al. Complement C5a receptors and neutrophils mediate fetal injury in the antiphospholipid syndrome. J Clin Invest 2003;112(11):1644-1654

71 Holers VM, Girardi G, Mo L, et al. Complement C3 activation is required for antiphospholipid antibody-induced fetal loss. J Exp Med 2002;195(02):211-220

72 Larsen JB, Andersen AS, Hvas CL, et al. Lectin pathway proteins of the complement system in normotensive pregnancy and preeclampsia. Am J ReprodImmunol 2019;81(04):e13092

73 Chaturvedi S, Braunstein EM, Yuan X, et al. Complement activity and complement regulatory gene mutations are associated with thrombosis in APS and CAPS. Blood 2020;135(04): 239-251
74 Tektonidou MG, Andreoli L, Limper M, et al. EULAR recommendations for the management of antiphospholipid syndrome in adults. Ann Rheum 2019;0:1-9

75 Choi M, Butler E, Clarke A, Girard LP, Gibson P, Skeith L. Managing pregnancy-associated clinical emergencies in systemic lupus erythematosus: a case-based approach. Expert Rev Clin Immunol 2020;16(01):5-22

76 Kutteh WH. Antiphospholipid antibody-associated recurrent pregnancy loss: treatment with heparin and low-dose aspirin is superior to low-dose aspirin alone. Am J ObstetGynecol 1996;174 (05):1584-1589

77 Farquharson RG, Quenby S, Greaves M. Antiphospholipid syndrome in pregnancy: a randomized, controlled trial of treatment. ObstetGynecol 2002;100(03):408-413

78 Goel N, Tuli A, Choudhry R. The role of aspirin versus aspirin and heparin in cases of recurrent abortions with raised anticardiolipin antibodies. Med Sci Monit 2006;12(03):CR132-CR136

79 Laskin CA, Bombardier C, Hannah ME, et al. Prednisone and aspirin in women with autoantibodies and unexplained recurrent fetal loss. N Engl J Med 1997;337(03):148-153

80 Rai R, Cohen H, Dave M, Regan L. Randomised controlled trial of aspirin and aspirin plus heparin in pregnant women with recurrent miscarriage associated with phospholipid antibodies (or antiphospholipid antibodies). BMJ 1997;314(7076):253-257

81 van Hoorn ME, Hague WM, van Pampus MG, Bezemer D, de Vries JIP; FRUIT Investigators. Low-molecular-weight heparin and aspirin in the prevention of recurrent early-onset pre-eclampsia in women with antiphospholipid antibodies: the FRUIT-RCT. Eur J Obstet Gynecol Reprod Biol 2016;197:168-173

82 Hansen AT, Sandager P, Ramsing M, et al. Tinzaparin for the treatment of foetal growth retardation: an open-labelled randomized clinical trial. Thromb Res 2018;170:38-44

83 Lockshin MD, Kim M, Laskin CA, et al. Prediction of adverse pregnancy outcome by the presence of lupus anticoagulant, but not anticardiolipin antibody, in patients with antiphospholipid antibodies. Arthritis Rheum 2012;64(07):2311-2318

84 Sciascia S, Branch DW, Levy RA, et al. The efficacy of hydroxychloroquine in altering pregnancy outcome in women with antiphospholipid syndrome. ThrombHaemost 2016;115:285-290

85 Schreiber K, Breen K, Cohen H, et al. HYdroxychloroquine to improve pregnancy outcome in women with AnTIphospholipid Antibodies (HYPATIA) protocol: a multinational randomized controlled trial of hydroxychloroquine versus placebo in addition to standard treatment in pregnant women with antiphospholipid syndrome or antibodies. Semin ThrombHemost 2017;43(06):562-571 